\title{
Poetic expressions of transdisciplinary food systems collaborations
}

SPECIAL ISSUE: MORE THAN VALUE\$ IN THE FOOD SYSTEM THE UNIVERITY OF VERMONT
AGRICULTURE \&
LIFE SCIENCES

Submitted February 20, 2020 / Revised June 4, July 2, and July 22, 2020 / Accepted July 22, 2020 /

Published online September 17, 2020

Citation: Heiss, S. N., Daigle, K., \& Kolodinsky, J. (2020). Poetic expressions of transdisciplinary food systems collaborations. Journal of Agriculture, Food Systems, and Community Development, 9(4), 15-28.

https://doi.org/10.5304/jafscd.2020.094.028

Copyright (C) 2020 by the Authors. Published by the Lyson Center for Civic Agriculture and Food Systems. Open access under CC-BY license.

\begin{abstract}
Transdisciplinary research, involving scholars and practitioners from a variety of fields, disciplines, and experiences, helps identify and explore the dynamic, multidimensional intersections among food systems challenges. While a valuable practice for exploring the food system in a meaningful way, transdisciplinary research in and of itself is a complex collaborative process. To support efforts for transdisciplinary approaches to food systems challenges, the Food Systems department at the University of Vermont sponsored a two-day workshop. This article uses poetic transcription

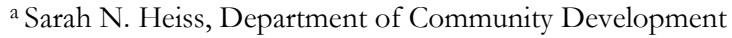
and Applied Economics; 208F Morrill Hall; 146 University Place; University of Vermont; Burlington, VT 05405 USA.

$\mathrm{b} *$ Corresponding author: Kerry Daigle, Department of Community Development and Applied Economics; 002 Morrill Hall; 146 University Place; University of Vermont; Burlington, VT 05405 USA; +1-802-656-2001; kjdaigle@uvm.edu

' Jane Kolodinsky, Department of Community Development and Applied Economics; 202 Morrill Hall; 146 University Place; University of Vermont; Burlington, VT 05405 USA.
}

drawn from participants' written evaluation of the workshop to analyze and share themes in experiences with transdisciplinary research and collaborations. The results, presented in a set of poems, promote conversation and understanding around the importance of transdisciplinary collaborations, as well as their challenges and opportunities for food systems.

\section{Keywords}

Food Systems, Workshop Evaluation, Poetic Transcription, Transdisciplinary Research

\section{Introduction}

Conceptualizing value as more than just economic returns requires practitioners and scholars to view food systems as interconnected material, built, and social systems (Francis et al., 2008; Restrepo, Lelea, Christinck, Hülsebusch, \& Kaufmann, 2014;

\section{Funding Disclosure}

The workshop featured in this paper was funded by the UVM Graduate College and the UVM Food System Graduate Program. 
Valley, Wittman, Jordan, Ahmed, \& Galt, 2018). Transdisciplinary research, involving scholars and practitioners from a variety of fields, disciplines, and experiences, helps identify and explore the dynamic, multidimensional intersections among these systems. In particular, when multiple scholars and practitioners work collaboratively, they can use multiple lenses and a variety of datasets that transcend any one discipline. In collaboration on a project, their knowledge, skills, and experiences become synergistic. They are better able to identify complex problems facing a food system and generate complex interpretations of a particular phenomenon (Ellingson, 2009).

Just as food systems problems are complex, so are the solutions. Transdisciplinary research is valuable to food systems because it is well-positioned to develop, implement, and share meaningful solutions that address multidimensional needs, rather than just one dimension of a single need. These collaborations should generate more creative, responsible, and sustainable solutions to complex issues in the food system.

While a valuable practice for exploring the food system in a meaningful way, transdisciplinary research in and of itself is a complex process (Wickson, Carew, \& Russell, 2006). To support efforts for transdisciplinary approaches to researching value in the food systems, the Food Systems department at the University of Vermont sponsored a two-day workshop on May 31 and June 1, 2019. The purpose of the workshop was to produce articles that highlight transdisciplinary perspectives of value in the food system. In addition to providing dedicated time to work on team articles related to the special issue of this journal, the workshop included several sessions related to defining value in the food system and transdisciplinary research processes and experiences. For example, each faculty member gave a short talk regarding their involvement in previous transdisciplinary projects. Other sessions included publication strategies for transdisciplinary work with editors of the Journal of Agriculture, Food Systems and Community Development (JAFSCD), transdisciplinary teamwork with experienced researchers, and transdisciplinary grant management with principal investigators.
With the goal of supporting food systems through research, the workshop aimed to increase and learn more about transdisciplinary collaboration. Following the workshop, the host collected program evaluations of the workshop focused on the topics, skills, and experiences that resonated with participants. As intended, the workshop provided space and time for teams to write articles for JAFSCD. An initial reading of the evaluations suggested, however, that the workshop produced more than publishable articles. The workshop created a space for participants to reflect on how their experiences of transdisciplinary research as a process and an outcome resonated or departed from those of others.

While the synergy produced in research collaboration is fairly well cited, the literature is limited in its ability to explain "the specific skills and approaches needed to spearhead or participate on a successful, highly collaborative and integrated research team" (Bennett \& Gadlin, 2012, p. 3). Beyond highlighting processes and frameworks needed to participate in collaborative research teams, the workshop evaluation responses also addressed how food systems and transdisciplinary research both represent and function as interconnected, complex material, built, and social systems.

With this study, our goal is to highlight the experiences and opinions of the participants based on the workshop and past collaborative experiences. The current article uses poetic transcription to represent how participants' experiences of the workshop and transdisciplinary research collaboration reflect, reinforce, and challenge each other. Under the assumption that transdisciplinary research is important to understand the complexities of the food system, our goal is to facilitate reflection that helps readers better understand their current collaborative experiences, identify what they need to know in order to advance their collaborative potential or output, and guide choices for further collaborations. Future workshop planners may also find these poems helpful as they plan activities to foster successful collaborative and integrated research teams.

\section{Workshop Participants}

The workshop participants were a transdisciplinary 
group, ranging in professional roles within food system research, levels of academic training and standing, disciplinary backgrounds, and institutional affiliations. All were currently engaged in food systems research. Originally, 11 faculty members working in the area of transdisciplinary food systems were invited to participate in a transdisciplinary workshop. These faculty members shared the invitation with fellow faculty and graduate students who might be interested in joining the workshop (the total number of faculty and students reached is not known). To accept, participants had to submit (1) a short abstract of a transdisciplinary project they were working on or planned to write about for a JAFSCD special issue, related to the topic of value in the food systems, and (2) the name of at least one graduate student who would work on the paper and attend the workshop with them. A total of 21 faculty members and graduate students responded and were included in the workshop cohort.

Attendees were predominantly female (69\%). Those in attendance included graduate students, professors, research professionals, and a public health professional. Participants were employed by three different universities, one extension agency, and a public health department in three different states (Vermont, New York, and Washington). Graduate students were all a part of the masters' program in Community Development and Applied Economics at the University of Vermont. Those included on the original list of participants, but not in attendance, included an assistant professor from a physical science discipline and his graduate student, a female agricultural extension agent, and a female research professional with a master's degree in a social science discipline. The absent individuals all resided in the same state as the workshop session. Each reported time conflicts as their reason for not attending.

\section{Workshop Feedback Tool}

After the two-day workshop on transdisciplinary approaches to exploring value in the food system, the participants completed a workshop feedback survey. The purpose of this survey was to better understand participants' experiences and attitudes around transdisciplinary work and workshop activities. The survey included open and closeended questions. Close-ended questions asked participants to identify as either a faculty or student and to rank on a Likert scale whether or not they feel they learned more about transdisciplinary research, found the material useful, and are more likely to engage in transdisciplinary research in the future. Open-ended prompts were then given for participants to record three things that came to mind when asked about each of the workshop sessions, as well as any additional information they wanted to include.

\section{The Emergence of a Transdisciplinary Project}

The current study emerged from an interesting place of vulnerability for all three authors. Jane Kolodinsky (\#3 author), a professor in applied economics at the professor rank, was the principal investigator on the grant that funded the workshop. Sarah Heiss and Kerry Daigle (the \#1 and \#2 authors, respectively) were participants. Sarah is an associate professor in communication studies, and Kerry is a graduate student in community development. During the workshop, Sarah talked to Kerry and Jane about a transdisciplinary food systems manuscript using poetic transcription she was completing for a different publication. This was Sarah's first time using the method and Kerry and Jane's first exposure to the method.

Following the workshop, Jane reviewed the survey responses and found the open-ended feedback to include compelling and forceful reflections on the workshop, as well as on the transdisciplinary process itself. She reached out to Sarah and Kerry about using the evaluation contents as a dataset. Before reviewing the evaluations, the researchers obtained IRB Human Subjects Approval. The study was categorized as secondary research on a dataset, as the original purpose of the surveys was for evaluation of the workshop for future improvement within the department. Evaluations were anonymous, and participants were notified via email that their responses would be included in this analysis. Once IRB approval was obtained, the three authors reviewed the responses and decided together to use thematic analysis and poetic transcription for the analysis and write-up. Sarah Heiss 
provided methodological readings and basic training sessions for the team before and during the analysis and writing processes.

\section{Relevance and Rationale}

Poetic transcription, "the creation of poem like compositions from the words of interviewees" (Glesne, 1997, p. 3), is a relevant method for analyzing and representing qualitative datasets related to complex systems and experiences. Cahnmann (2003) argued that poetic transcription provides new ways of seeing previously hidden complexity and contradictions that improve understanding of social phenomena.

Because it is a useful and relevant method for analyzing complex social processes and systems, a variety of social science disciplines have used this research method over the last 20 years, including but not limited to sociology, education, social work, communication studies, and anthropology (Becker, 1999; Calafell, 2004; Carr, 2003; Hartnett, 2003; Nichols, Biederman, \& Gringle, 2014; Patrick, 2016; Poindexter, 2002; Teman, 2010; Richardson, 1994).

Poetic transcription has also been used as a tool to explore and teach about food systems. For example, poetic transcription has been used to research food systems topics ranging from socioecological transformations linked to changes in grazing practices and the livestock industry (Fernández-Giménez, 2015) to the experience of loss of appetite among cancer patients (Souter, 2005). Poetry has also been used as a tool to teach food system issues, including agricultural awareness (Bjorsen \& Emery, 2002), biological and agricultural engineering (Christy \& Lima, 2007), conservation science (Januchowski-Hartley et al., 2018), hunger and food insecurity (Huye, 2015), and environmental sustainability (Anabaraonye, Nji, \& Hope, 2018).

The current study seeks to foster transdisciplinary collaboration and training within food systems, as well as to contribute to the growing body of food systems scholarship and practice using poetic transcription. This section begins with a brief rationale for using poetic transcription to analyze and share the complex themes that enable and constrain transdisciplinary collaboration in food systems. We next describe the poetic transcription procedures used in this study. Finally, we invite audiences to read a set of poems based on participant responses to the workshop.

\section{Background in Poetic Transcription}

While research is traditionally written in prose, Richardson (2001) believed that researchers, participants, and research audiences could benefit from diversifying the ways in which data is analyzed and represented. Poetic transcription provides a departure from traditional prose. Cahmann-Taylor (2008) explained the complementary nature of poetry and prose well: "just as the microscope and camera have allowed different ways for us to see what would otherwise be invisible, so too poetry and prose are different mediums that give rise to ways of saying what might not otherwise be expressed" (p. 16). While poetic transcription serves the same goals as systematically analyzing and highlighting patterns in participants' voices and experiences (Curtin \& Fossey, 2007), its ability to complement or shift the focus of prose research makes it a valuable addition to food systems and transdisciplinary research. Many scholars highlight the ability of poetic transcription to shift the power dynamics among the participant, researcher, and reader.

Poetic transcription, like other forms of qualitative analysis, empowers participants by placing their voices in the "center of inquiry, analysis, and discussion rather than on the margins" (Tillman, 2006 , p. 282). Poems resulting from poetic transcription are composed of words taken directly from a qualitative dataset (Glesne, 1997; Richardson, 1994; Simpson \& Quigley, 2016). A poem or set of poems can include direct quotes from a single participant interview or survey (for examples, see Glesne, 1997; Poindexter, 2002). Rather than committing a poem per participant, a poem or set of poems can also be multivocal compositions, consisting of direct quotes from multiple participants to capture the recurrent nature of themes within and across participants' comments (for examples, see Hartnett, 2003; Teman, 2010). A poem or set of poems can focus on the multidimensional nature of a theme or multiple themes simultaneously. By doing so, poetic transcription 
serves to simplify complex themes and/or complicate themes once thought to be simple concepts (Ellingson, 2009).

Although poetic transcription empowers participants, researchers still have a role in shaping the research project's design, data collection, analysis methods, and representation (Ellingson, 2009). This method does not uphold certain standards of validity and reliability expected by quantitative researchers, nor does it try to do so. Furman (2006) asserts, "not all research must have as its ultimate goal the generation of knowledge that is generalizable" (p. 3). Rather than seeking objectivity in their actions, researchers using poetic transcriptions privilege subjectivity and reflexivity, which includes thoughtful, conscious self-awareness. Researchers must constantly think about how those intersections shape or are shaped by the research process. For example, with poetic transcription, researchers much consider why they are using the method, whose voices to include, and what methods to use when arranging the phrases and stanzas to create the poems (Ho, 2012). Researchers also exercise reflexivity by recognizing that they themselves can be transformed through the research process. Through thoughtful reflection research that centers participant voice and audience experience, researchers using qualitative methods, including poetic transcription, support the transferability of results. Rather than seeking generalizable results that are representative of a larger population, the transferability of results means that readers are given the opportunity to decide the degree to which results can be used in their unique situations (Maxwell \& Chmiel, 2014).

Unlike conventional research write-ups, which require the author to explicitly interpret the themes or data, poetic transcription invites readers to have an active role in experiencing and making sense of the data and results. The researcher is not positioned as "the sole legitimate carrier of knowledge" (Richardson, 2001, p. 877). Rather, authors create spaces that share and evoke emotion, engaging readers in a creative relationship that moves them beyond passivity to co-creation (Furman, 2006). By "highlighting larger segments of participants' words than usually occurs in conventional reports" (Ellingson, 2009, p. 65), poetic transcription allows readers to have an increased opportunity to experience participant(s), contexts and the nuanced connection among themes.

\section{Current Methodology}

The goal of this study was to write poems that would highlight the experience and opinions of the participants as they experienced the workshop and reflected on past collaborative experiences. Guidance on poetic transcription is being included increasingly in qualitative research handbooks, though no single method has been identified (Faulkner, 2009; Harter, Peterson, McKenna, \& Torrens, 2012; Madison, 2012; Richardson, 2001). Across sources, the common methodological recommendations include crafting poems that use exclusively words and phrases from participants, in order to represent the most powerful and relevant themes. Participants' words are condensed and arranged in ways that communicate the themes and allow room for interpretation.

The authors used thematic analysis methods to inductively identify patterns in the dataset. Thematic analysis is a commonly used cyclical and continuous method of making sense of, reducing, and explaining patterns within and across qualitative datasets (Braun \& Clarke, 2006; Lindlof \& Taylor, 2011). In the initial stages of analysis, each author worked independently to read and open-code the open-ended survey responses for concepts related to transdisciplinary collaboration in the food system. Upon a second review, authors collapsed related codes into each other to create categories or patterns. After two weeks, the authors met and discussed the categories we identified independently. Drawing on independently derived categories, the authors identified five central themes that are reoccurring, repetitive, and forceful (Owen, 1984) within and across participants' comments: transdisciplinary research is (1) an ongoing process; (2) a complicated and dynamic process; (3) valuable to the food system; (4) requires effective communication; and (5) valued more by some than others.

Guided by these themes, the authors individually began the process of poetic transcription. Standards of rigor associated with poetic transcription reflect the ability of a poem or set of poems to express and share meaning. The authors individu- 
ally worked to select phrases that represented the emergent themes. Each author juxtaposed these phrases to create thematically driven poems (Ho, 2012). After two weeks, the three authors met and read their poems aloud. The authors discussed commonalities and departures in style, form, and representation of the themes. Some poems, written by different authors, were then combined to add increased dimension to a given theme. While faithfully representing the words and meanings of the original dataset, the authors also worked together to adjust issues related to form, pattern, and line spacing for aesthetics and impact, and editing things such as word spacing. Poindexter (2002) described this step as "diamond cutting ... the chipping away of all but the phrases and stanzas that seemed most evocative in emotion and clarity" (p.709). Some poems were eliminated in favor of what the team considered stronger poems on the same theme. To capture the recurrent nature of themes within and across participants' comments, the resulting set of poems represents a composite of direct quotes from multiple participants. Each poem was reviewed several times to confirm that any given poem read alone resonated with one or more themes and that, when read as a set, the poems served to both complicate and simplify the original themes (Mears, 2009).
The poems were originally written with the intention of inviting readers to interpret the themes without the authors' guidance. Introductions were added to the poems after the fact and upon editorial request. The goal of the introductions is to provide a basic framing for the poems, while simultaneously maintaining readers' autonomy to have independent interpretations and responses. While not a consistent practice in poetic transcription, introductory content is comparable to the writing styles seen in other published poetics research (for example, see Harter et al., 2012)

The poems that follow represent forceful and recurring themes within and across workshop feedback. The authors invite the reader to consider the themes that emerge within individual poems, as well as across the set of poems. The hope is that readers from a variety of disciplines, professions, and ranks will suspend themselves in these poems-reflecting on how the themes expressed through these poems resonate with their personal transdisciplinary collaborative experiences. In addition, readers should consider how this reading experience may reinforce or challenge how other articles in this special issue of the Journal of Agriculture, Food Systems, and Community Development use transdisciplinary collaboration to examine or define value in the food system.

\section{Process Theme Poems}

\section{It doesn't just happen}

(What did you like best) Time to share research perspectives to move the field

Transdisciplinary research doesn't just happen

Need trust

Reflection

Time

Getting the time

More time 


\section{We carved out time for the transdisciplinary workshop}

\section{It takes time to LEARN ABOUT this transdisciplinary work.}

Time

To learn a new vocabulary; it's hard enough to know the words of my own discipline

To change my perspective; it's hard enough to understand my discipline's perspective

To appreciate my colleagues who have different training

To practice respect beyond the giants in my own field

\section{It takes time to DO this transdisciplinary work.}

Time

To interpret the theme across disciplines

To harmonize our writing

To synthesize our drafts

\section{But still there isn't enough time}

No time

To think

To discuss

To write

To reflect

How do we make time for this transdisciplinary work in a world deep in disciplinary thought?

Yet, we carved out time for a transdisciplinary workshop.

The poems entitled "It doesn't just happen" and "We carved out time for a transdisciplinary workshop" frame transdisciplinary research as an ongoing, complicated, and dynamic process. In addition to completing the tasks associated with any research project, such as research writing, transdisciplinary research requires more time to develop relationships, mutual respect, and shared understanding across disciplines. The poems highlight the extra demands this need for time puts on individuals already struggling to find time to do research and grow within their own disciplinary boundaries.

\section{Roles and Practices Theme Poems}

\section{Parts}

Baby steps forward; giant steps backward.

Falter, embrace, hesitate, jump in.

We are in this together because we choose to be. 
Building respect, trust and rapport,

Fostering appreciation,

Learning from one another,

Leveling the playing field.

But wait!

It's not a level playing field.

There needs to be a leader.

We have to be accountable.

There are rules.

A hierarchy exists.

Is this transdisciplinary work an oxymoron?

Build trust.

Do your part.

Speak up.

\section{The Key}

Transdisciplinary research is hard to achieve,

Communication is key.

Teamwork is important,

Communication is key.

Leadership can determine dynamics,

Communication is key.

Trust,

Respect,

Boundaries.

Politics and personalities take time and effort,

... but are worth it.

... so keep trying. 
Reinforcing and building on the prior two poems, which situated transdisciplinary research as dynamic and complicated processes, the poems entitled "Parts" and "The Key" highlight important practices or roles within transdisciplinary processes. "Parts" suggests that transdisciplinary team members should "do your part." Specifically, the poems recognize effective leadership, engagement, and communication as important elements. Leadership is recognized as an important role within transdisciplinary teams. In "Parts," one participant suggests that "leadership can determine the dynamics"; leaders do not just manage the project tasks and timelines. Leaders' role also included managing the team climate. Specifically, leaders attend to issues of power by "leveling the playing field." Participants wanted leaders who could facilitate appreciation and learning across disciplines. While leaders would have some level of power over the team, it is important to note that strong leaders were not defined by their discipline or formal role on a grant application; rather, they were competent communicators able to facilitate task completion and respect among team members. The other poem, "The Key," demonstrates how communication skills transcend the leader role. Transdisciplinary team members need to exercise communication competence as they engage in teamwork and build trust and respect, as well as manage boundaries, personalities, and politics. It is interesting to note that while these poems highlight "do your part," participants did not focus on researchspecific tasks, such as grant administration, data collection, analysis, or write-up.

\section{Expression of Value Theme Poems}

\section{Value Varies}

Appreciate colleagues,

Values are constructed and context dependent.

Collaborate with a new colleague in a discipline you haven't heard before,

There are multiple perspectives.

Make sure the lesser discipline gets their voices heard,

Values vary by culture.

[There are] pitfalls of transdisciplinary as a social scientist,

"tokenism" is still rife in academic circles.

Transdisciplinary relationships can last,

Common language and common vision are needed to make it happen.

What is one thing you would have like to have seen covered?

The hard scientists' perspective. 


\section{Where is the Natural Scientist?}

Cross-fertilization of ideas.

Everyone's research -

One size does not fit all.

Where is the natural Scientist?

Don't be afraid to ask.

Effective teams are hard, but worth it.

Communication is key.

Sometimes people stray.

Where is the natural scientist?

Don't be afraid to ask.

Values vary by culture.

Values are constructed and context dependent.

Value expression vs constraints revealed.

Where is the natural Scientist?

Don't be afraid to ask.

Be ever mindful of including others from the beginning of the project.

Don't be afraid to ask.

Building on the prior poems, "Value Varies" and "Where is the Natural Scientist?" highlight how issues related to disciplinary values shape the dynamic and complicated processes of transdisciplinary research teams. While many participants expressed a desire to work in transdisciplinary teams because they thought it was valuable to the food system, they also said that they did not think members of every discipline felt this way. Specifically, a tension between social scientists and natural scientists emerged. One participant felt that they were seen as "token" social scientists when invited onto grants for which the primary investigator was a natural scientist. Other participants asked, "where is the natural scientist?" This was likely a reflection of the workshop, with only social scientists in attendance. However, the comments during the workshop and in the feedback also highlighted that, although natural scientists did not accept the invitation to participate in this transdisciplinary event nor submitted an abstract and did not attend, it was still worth asking them to collaborate. The concern over including these voices or strengthening collaboration with researchers from natural sciences is important to food systems research. It is interesting to note that the social scientists who participated did not comment on the lack of participation from the humanities in transdisciplinary projects. While this study cannot determine why the absence of the humanities did not appear in evaluations, it is worthwhile to note that the absence of this group may indicate a disconnect between the social sciences and humanities and point toward yet another opportunity for collaboration across disciplines. 


\section{Discussion}

When addressing researcher-stakeholder relationships in food systems, Lamine (2018) argued that "acknowledging the variety of values and interests involved and constructing a collective 'intelligence' of the situation and processes" (p. 9) is essential. The Food Systems department at the University of Vermont hosted a workshop to learn about and support transdisciplinary food system research. An outcome of this workshop was a collection of articles for a special issue of JAFSCD on the topic of "more than value $\$$ in the food system." In addition to articles, responses to a workshop evaluation provided scholar and practitioner accounts of what it is like to engage in transdisciplinary work and insight for future workshops. Additionally, the workshop evaluation form captured participants' experiences regarding the value of such collaborative efforts in the food system. These evaluation forms became a dataset for the current study. The results of a poetic analysis of this dataset have important implications for current and future conversations in food systems research and practice.

\section{Theoretical Implications}

The themes in these poems speak directly to current conversations in food systems research. While most of the poems explicitly reference the tensions related to resources, relationships, or power dynamics, the poems simultaneously convey a positive or optimistic tone. Participants reframe collaborative challenges as necessary team dynamics that can be managed through communication, time allocation, reflection, relationship-building, and good leadership.

In addition to the belief that team dynamics can be managed, participants pushed further, suggesting that they should be managed. This finding is consistent with Lamine (2018), who argued that collaborative dynamics should be managed to develop cohesive narratives of food system problems and research agendas. Pointing to the value of transdisciplinary work, the participants were driven to seek out and manage team dynamics by their desire to understand the complexity of food systems. In one participant's words, "Effective teams are hard, but worth it." Research teams and researcher-stakeholder relationships should prioritize team management in setting research agendas. This finding is valuable because it demonstrates the value of collaboration to researchers, as well as some of the processes that enable and constrain collaboration.

While the process of research collaboration and teaming has been examined in other disciplines, such as the medical fields (see Bennett, \& Gadlin, 2012), it is not well examined within food systems research. Future research should examine the interpersonal processes that shape and are shaped by food systems research team processes. For example, future research may quantitatively investigate instances of collaboration across disciplines involved in food systems research or analyze relevant disciplines' perspectives directly as they relate to collaborating across natural sciences, social sciences, and the humanities. These findings would foster increased collaborative potential within food systems research.

The use of poetic transcription makes novel contributions to methodical approaches to understanding how food systems research shapes and is shaped by social processes and complex systems. Cahnmann (2003) argued that poetic transcription provides new ways of seeing previously hidden complexity and contradictions that improve understanding of social phenomena. Poetry's ability to synthesize complex data into concise, yet evocative, text mirrors the need for food systems collaborations that can establish common goals among sometimes competing perspectives. In addition to bringing participant voices together, the poetic form provided an opportunity for the reader to uniquely experience the words of participants, in both complex and accessible ways, that traditional forms of qualitative research papers would not allow (Canniford, 2012; Ward, 2011). We believe that analyzing and delivering themes through poetic transcription acknowledges, as Lamine (2018) described, the variety of values involved in constructing a collective intelligence.

\section{Practical Implications}

The themes in these poems speak directly to current conversations in food systems practice. This workshop is one example of ways scholars and 
practitioners can come together to gain skills toward more effective transdisciplinary collaborations. The theme of "process" in the analysis suggests that these events are necessary and that, without doing the work to learn effective skills for transdisciplinary work, it would be difficult for teams to come together productively to address food systems topics.

The results are valuable because they could help future workshop planners develop formal training experiences to foster increased collaborative potential in their food systems. Specifically, these results suggest three techniques for hosting effective workshops on transdisciplinary food systems research:

\section{Purposefully recruit researchers who operate from diverse paradigms.}

A common frustration among participants was the lack of attendance by natural scientists. In the future, inviting scholars from many different disciplines may be useful to anticipate a low attendance rate by scholars from the hard sciences and invite a greater number of participants from these disciplines. While the participants did not recognize humanities and arts researchers as missing, we would like to suggest that these scholars also be actively recruited.

\section{Address effective communication strategies.}

The analysis suggests that successful communication is a common concern among scholars and practitioners interested in transdisciplinary work. Future workshops might prioritize strategies for communicating across actors in a way that honors the strengths of each unique disciplinary practice.

\section{Validate the factors that constrain collaborative research.}

Results convey the feeling that time is a barrier to reaching transdisciplinary food systems research goals. Similar to the workshop evaluated in this paper, future events should include large windows of time dedicated to writing in research teams in addition to hands-on, teambuilding activities.

In addition to providing themes for workshop leaders and educators, the poetic results of this study are uniquely valuable because they also yielded content for future workshops. The results in poetic form are valuable to future transdisciplinary food systems collaboration because their themes and form are accessible to audiences of varying disciplines, professions, reading levels, and quantitative reasoning skills (Cahnmann, 2003). Additionally, unlike more traditional representations of results, the poetic form of our results allows planners to create participatory learning opportunities. Poetry can provide "an avenue for communication" among students (Gunn, 2012, p. 25.1132.3). Participants can quickly read the multivocal accounts represented in the poems and then talk about how complex topics, such as power or teaming processes, are represented in the poems and in their own teaming experiences. These findings contribute to ongoing examples of poetry as a tool for teaching about food systems (Anabaraonye et al., 2018; Bjorsen \& Emery, 2002; Christy \& Lima, 2007; Huye, 2015).

\section{Conclusion}

This study highlights the experiences of researchers and practitioners conducting transdisciplinary research to address challenges in the food system. The key findings demonstrate that transdisciplinary research requires time for developing relationships and shared understanding across disciplines, open communication and engagement from all participants, and a conscious effort to value all disciplines' perspectives equally. These insights contribute to ongoing efforts to encourage transdisciplinary research in the food system, as well as offer practical suggestions for planning workshops for researchers and practitioners to both experience and develop strategies for transdisciplinary collaboration.

To maintain the readers' active participation in research using poetic transcription, this article concludes in an invitational tone. Readers are invited to reflect on their own values, practices, and experiences regarding transdisciplinary research. Of 
what value is transdisciplinary research to food systems? How do your values, practices, and experiences reinforce, challenge, or complicate transdisciplinary research collaboration? Are you included or including others in your pursuits within the food system?

\section{References}

Anabaraonye, B., Nji, I. A., \& Hope, J. (2018). Poetry as a valuable tool for climate change education for global sustainability. International Journal of Scientific \& Engineering Research, 9(9), 81-84. Retrieved from https://www.ijser.org/

Becker, B. (1999). Narratives of pain in later life and conventions of storytelling. Journal of Aging Studies, 13(1), $73-87$. https://doi.org/10.1016/S0890-4065(99)80007-3

Bennett, L. M., \& Gadlin, H. (2012). Collaboration and team science: From theory to practice. Journal of Investigative Medicine, 60(5), 768-775. https://doi.org/10.2310/JIM.0b013e318250871d

Bjornsen, A., \& Emery, P. (2002). Agricultural awareness through poetry, grades 9-10. California Foundation for Agriculture in the Classroom. Retrieved from https://learnaboutag.org/resources/table_poetry.cfm

Braun, V., \& Clarke, V. (2006). Using thematic analysis in psychology. Qualitative Research in Psychology, 3(2), 77-101. https://doi.org/10.1191/1478088706qp063oa

Cahnmann, M. (2003). The craft, practice, and possibility of poetry in educational research. Educational Researcher, 32(3), 29-36. https://doi.org/10.3102/0013189X032003029

Cahnmann-Taylor, M. (2008). Poetry in qualitative research. In L. M. Given (Ed.), The SAGE Encyclopedia of Qualitative Research Methods (pp. 637-640). Thousand Oaks, CA: SAGE.

Calafell, B. M. (2004). Disrupting the dichotomy: "Yo Soy Chicana /o?" in the New Latina /o South. The Communication Review, 7(2), 175-204. https://doi.org/10.1080/10714420490448705

Canniford, R. (2012). Poetic witness: Marketplace research through poetic transcription and poetic translation. Marketing Theory, 12(4), 391-409. https://doi.org/10.1177/1470593112457740

Carr, J. M. (2003). Poetic expressions of vigilance. Qualitative Health Research, 13(9), 1324-1331. https://doi.org/10.1177/1049732303254018

Christy, A. D., \& Lima, M. (2007). Developing creativity and multidisciplinary approaches to teaching engineering problem-solving. International Journal of Engineering Education, 23(4), 636. Retrieved from https://www.ijee.ie/

Curtin, M., \& Fossey, E. (2007). Appraising the trustworthiness of qualitative studies: Guidelines for occupational therapists. Australian Occupational Therapy Journal, 54(2), 88-94. https://doi.org/10.1111/j.1440-1630.2007.00661.x

Ellingson, L. L. (2009). Engaging crystallization in qualitative research: An introduction. Thousand Oaks, CA: SAGE. https://doi.org/10.4135/9781412991476

Faulkner, S. L. (2009). Poetry as method: Reporting research through verse. Walnut Creek, CA: Left Coast Press.

Fernández-Giménez, M. E. (2015). "A shepherd has to invent”: Poetic analysis of social-ecological change in the cultural landscape of the central Spanish Pyrenees. Ecology and Society, 20(4), 29. http://dx.doi.org/10.5751/ES-08054-200429

Francis, C. A., Lieblein, G., Breland, T. A., Salomonsson, L., Geber, U., Sriskandarajah, N., \& Langer, V. (2008). Transdisciplinary research for a sustainable agriculture and food sector. Agronomy Journal, 100(3), 771-776. https://doi.org/10.2134/agronj2007.0073

Furman, R. (2006). Poetic forms and structures in qualitative health research. Qualitative Health Research, 16(4), 560-566. https://doi.org/10.1177/1049732306286819

Glesne, C. (1997). That rare feeling: Re-presenting research through poetic transcription. Qualitative Inquiry, 3(2), 202221. https://doi.org/10.1177/107780049700300204

Gunn, C. J. (2012, June). Revisiting a liberal activity in a college of engineering: Engineers as poets 10 years later. Paper presented at the 2012 ASEE Annual Conference \& Exposition, San Antonio, Texas. https://peer.asee.org/21889

Harter, L. M., Peterson, B. L., McKenna, T., \& Torrens, A. (2012). Poetic interpretations of storytelling. In L. M. Harter (Ed.), Imagining New Normals: A Narrative Framework for Health Communication (pp. 188-201). Kendall Hunt.

Hartnett, S. J. (2003). Incarceration nation: Investigative prison poems of hope and terror. Lanham, MD: Rowman Altamira. 
Ho, S. (2012, August). Poetic transcription as a way of data (re)presentation. Paper presented at the Association for Qualitative Reseach Conference 2012, Charles Darwin University, Northern Territory, Australia.

Huye, H. (2015). Using poetry and art analysis to evoke critical thinking and challenging reflection in senior-level nutrition students. Journal of Nutrition Education and Behavior, 47(3), 283-285. https://doi.org/10.1016/j.jneb.2015.01.007

Januchowski-Hartley, S. R., Sopinka, N., Merkle, B. G., Lux, C., Zivian, A., Goff, P., \& Oester, S. (2018). Poetry as a creative practice to enhance engagement and learning in conservation science. BioScience, 68(11), 905-911. https://doi.org/10.1093/biosci/biy105

Lamine, C. (2018). Transdisciplinarity in research about agrifood systems transitions: A pragmatist approach to processes of attachment. Sustainability, 10(4), 1241. https://doi.org/10.3390/su10041241

Lindlof, T. R., \& Taylor, B. C. (2011). Qualitative communication research methods. Thousand Oaks, CA: SAGE.

Madison, D. S. (2012). Critical ethnography: Method, ethics, and performance (2nd ed.). Thousand Oaks, CA: SAGE.

Maxwell, J. A., \& Chmiel, M. (2014). Generalization in and from qualitative analysis. In U. Flick (Ed.), The SAGE Handbook of Qualitative Data Analysis (pp. 540-553). Thousand Oaks, CA: SAGE.

Mears, C. L. (2009). Learning from the data. In C. L. Mears, Interviewing for education and social science research: The gateway approach (pp. 121-144). New York: Springer. https://doi.org/10.1057/9780230623774 7

Nichols, T. R., Biederman, D. J., \& Gringle, M. R. (2014). Using research poetics "responsibly": Applications for health promotion research. International Quarterly of Community Health Education, 35(1), 5-20. https://doi.org/10.2190/IQ.35.1.b

Owen, W. F. (1984). Interpretive themes in relational communication. Quarterly Journal of Speech, 70(3), $274-287$. https://doi.org/10.1080/00335638409383697

Patrick, L. D. (2016). Found poetry: Creating space for imaginative arts-based literacy research writing. Literacy Research: Theory, Method, and Practice, 65(1), 384-403. https://doi.org/10.1177/2381336916661530

Poindexter, C. C. (2002). Research as poetry: A couple experiences HIV. Qualitative Inquiry, 8(6), 707-714. https://doi.org/10.1177/1077800402238075

Restrepo, M. J., Lelea, M. A., Christinck, A., Hülsebusch, C., \& Kaufmann, B. A. (2014). Collaborative learning for fostering change in complex social-ecological systems: A transdisciplinary perspective on food and farming systems. Knowledge Management for Development Journal, 10(3), 38-59. Retrieved from https://www.km4djournal.org/

Richardson, L. (1994). NINE POEMS: Marriage and the family. Journal of Contemporary Ethnography, 23(1), 3-13. https://doi.org/10.1177/089124194023001001

Richardson, L. (2001). Poetic representation of interviews. In J. F. Gubrium \& J. A. Holstein (Eds.), Handbook of interview research: Context \& method (pp. 877-891). Thousand Oaks, CA: SAGE.

Simpson, A., \& Quigley, C. F. (2016). Member checking process with adolescent students: Not just reading a transcript. The Qualitative Report, 21(2), 376-392. Retrieved from https://nsuworks.nova.edu/tqr/

Souter, J. (2005). Loss of appetite: A poetic exploration of cancer patients' and their carers' experiences. International Journal of Palliative Nursing, 11(10), 524-532. https://doi.org/10.12968/ijpn.2005.11.10.19980

Teman, E. D. (2010). Now, he’s not alive. Qualitative Inquiry, 16(8), 611-611. https://doi.org/10.1177/1077800410374036

Tillman, L. C. (2006). Researching and writing from an African-American perspective: Reflective notes on three research studies. International Journal of Qualitative Studies in Education, 19(3), 265-287. https://doi.org/10.1080/09518390600696513

Valley, W., Wittman, H., Jordan, N., Ahmed, S., \& Galt, R. (2018). An emerging signature pedagogy for sustainable food systems education. Renewable Agriculture and Food Systems, 33(5), 467-480. https://doi.org/10.1017/S1742170517000199

Ward, A. (2011). "Bringing the message forward": Using poetic re-presentation to solve research dilemmas. Qualitative Inquiry, 17(4), 355-363. https://doi.org/10.1177/1077800411401198

Wickson, F., Carew, A. L., Russell, A. W. (2006). Transdisciplinary research: Characteristics, quandaries and quality. Futures, 38(9), 1046-1059. https://doi.org/10.1016/j.futures.2006.02.011 